\title{
Effect of 24-epibrassinolide on drought stress-induced changes in Chorispora bungeana
}

\author{
Y.H. LI ${ }^{1,2}$, Y.J. LIU ${ }^{1}$, X.L. XU ${ }^{1}$, M. JIN ${ }^{1}$, L.Z. $\mathrm{AN}^{1}$ and H. ZHANG ${ }^{1 *}$ \\ Key Laboratory of Arid and Pasture Agroecology of Ministry of Education, School of Life Sciences, \\ Lanzhou University, Lanzhou 730000, Gansu, P.R. China ${ }^{1}$ \\ Department of Life Sciences, Zhengzhou Normal University, Zhengzhou 450044, Henan, P.R. China ${ }^{2}$
}

\begin{abstract}
Brassinosteroids (BRs) have been proposed to increase the resistance of plants to drought stress. The effect of foliar application of $0.1 \mu \mathrm{M}$ 24-epibrassinolide (EBR) on chlorophyll (Chl) content, photosystem 2 (PS 2) photochemistry, membrane permeability, lipid peroxidation, relative water content (RWC), proline content, and the antioxidant system in drought-stressed Chorispora bungeana plants was investigated. The results showed that polyethylene glycol (PEG) induced water stress decreased RWC, Chl content and variable to maximum Chl fluorescence ratio $\left(\mathrm{F}_{\mathrm{v}} / \mathrm{F}_{\mathrm{m}}\right)$ less in plants pretreated with EBR than in non-pretreated plants. In addition, lipid peroxidation, measured in terms of malondialdehyde content, membrane permeability and proline content in drought-stressed plants were less increased in EBR pretreated plants, while antioxidative enzyme activities and reduced ascorbate and glutathione contents were more increased in EBR pretreated than in non-pretreated plants. These results suggested that EBR could improve plant growth under drought stress
\end{abstract}

Additional key words: antioxidative enzymes, brassinosteroids, chlorophyll, lipid peroxidation, membrane permeability, photosystem, proline, reactive oxygen species.

Drought is a major environmental factor restricting plant growth and productivity. Thus, development of methods to induce drought stress tolerance in plants is of vital importance. Water stress causes significant declines in leaf water potential and relative water content (RWC) and directly affects many aspects of plant physiology such as membrane stability, nitrate reductase activity, chlorophyll (Chl) content and photosynthetic parameters (Correia et al. 2006, Santos et al. 2009). Drought can also cause oxidative damage due to excessive generation of reactive oxygen species (ROS), which can cause deterioration of membrane lipids and proteins, leading to increased membrane leakage of solutes (Moran et al. 1994). However, plants evolved the defense system, which includes antioxidative enzymes [catalase (CAT, EC 1.11.1.6), peroxidases (POD, EC 1.11.1.7), superoxide dismutases (SOD, EC 1.15.1.1), glutathione reductase (GR, EC 1.6.4.2) and ascorbate peroxidase (APX, EC 1.11.1.11) ], low molecular mass antioxidants ascorbate (AsA), glutathione (GSH), and some compatible solutes such as betaines and proline (Foyer and Noctor 2005, Veljovic-Jovanovic et al. 2006).

Brassinosteroids (BRs) play an essential role in plant growth and development (Clouse and Sasse 1998). Moreover, BRs are recognized to have an ameliorative role in plants subjected to various biotic and abiotic stresses, such as high temperature (Ogweno et al. 2008), excess of heavy metals (Fariduddin et al. 2009), and

Received 23 April 2010, accepted 4 April 2011.

Abbreviations: APX - ascorbate peroxidase; AsA - reduced ascorbate; BRs - brassinosteroids; CAT - catalase; Chl - chlorophyll; EBR - 24-epibrassinolide; EDTA - ethylenediaminetetraacetic acid; EL - electrolyte leakage; $\mathrm{F}_{0}, \mathrm{~F}_{\mathrm{m}}$ - minimum and maximum fluorescence in dark-adapted leaves; $\mathrm{F}_{\mathrm{v}} / \mathrm{F}_{\mathrm{m}}$ - variable to maximum fluorescence ratio; GR - glutathione reductase; GSH - reduced glutathione; MDA - malondialdehyde; PEG - polyethylene glycol; PS 2 - photosystem 2; ROS - reactive oxygen species; RWC - relative water content; SOD - superoxide dismutase; $\Phi_{\mathrm{PS} 2}$ - the quantum yield of PS 2.

Acknowledgments: This study was supported by the National Natural Science Foundation of China (grant No. 30900172), the National Outstanding Youth Foundation of China (No. 30625008), and the Major Project of Cultivating New Varieties of Transgenic Organisms (2009ZX08009-029B, 2008ZX08009-003)

* Corresponding author; fax: (+86) 931 8625576, e-mail: zhanghua@1zu.edu.cn 
salinity (Ali et al. 2007). The aim of this study was to investigate effects of 24-epibrassinolide (EBR; one of the most active and stable forms of BRs) pretreatment for improving plants tolerance against drought stress and the role of the antioxidant defense system in this process.

Seeds of Chorispora bungeana Fisch. \& C.A. Mey, a herb plant of the family Brassicaceae, were surface sterilized with $1 \%$ sodium hypochlorite solution plus $0.1 \%$ Tween-20 and washed several times with deionized water. Cotyledons were cut off and planted on Murashige and Skoog (1962; MS) solid medium containing $0.2 \mathrm{mg} \mathrm{dm}^{-3}$ 2,4-dichlorophenoxyacetic acid and $0.2 \mathrm{mg} \mathrm{dm}^{-3}$ 6-benzyladenine. The cultures were grown under a 16-h photoperiod, irradiance of $120 \mu \mathrm{mol} \mathrm{m}^{-2} \mathrm{~s}^{-1}$ (supplied by cool white fluorescent tubes), relative humidity of $55 \pm 5 \%$, and temperature of $23 \pm 2{ }^{\circ} \mathrm{C}$. After $20 \mathrm{~d}$, growing tissues were transferred to MS solid medium containing $0.4 \mathrm{mg} \mathrm{dm}^{-3}$ gibberellin and $0.6 \mathrm{mg} \mathrm{dm}^{-3}$ kinetin. The regenerants were then subcultured every two weeks, and after several cycles, the plantlets were transferred to earthenware pots filled with soil and farmyard manure $(6: 1)$. Plants were watered with full strength Hoagland solution and when seedlings were approximately $5 \mathrm{~cm}$ tall, a $0.1 \mu \mathrm{M}$ aqueous EBR (Sigma Aldrich, St. Louis, USA) solution containing $0.1 \%$ Tween 20 was sprayed thrice on the leaves every $2 \mathrm{~h}$, with control plants similarly sprayed with water containing only Tween 20. The selected EBR concentration was based on earlier work performed by Xia et al. (2009). One day after spraying, drought stress was induced by watering the plants with the Hoagland solution containing $20 \%$ polyethylene glycol 6000 (PEG). The plants were divided into four groups: wellwatered and non-EBR treated (WW), drought stressed and non-EBR treated (DS), EBR treated and well watered $(\mathrm{EBR}+\mathrm{WW})$ and $\mathrm{EBR}$ treated and drought stressed $(\mathrm{EBR}+\mathrm{DS})$. Leaves were collected $72 \mathrm{~h}$ after PEG treatment, immediately frozen in liquid nitrogen, and stored at $-80{ }^{\circ} \mathrm{C}$ for the subsequent analyses.

Chl $a$ and $b$ were extracted using $80 \%$ acetone on ice and determined according to Lichtenthaler (1987). The Chl fluorescence parameters were measured on attached leaves using a portable pulse modulation fluorometer (PAM-2100, Heinz Walz, Effetrich, Germany). The minimum fluorescence $\left(\mathrm{F}_{0}\right)$ was read under a weak modulated light after $30 \mathrm{~min}$ of dark adaptation, and the maximum fluorescence $\left(\mathrm{F}_{\mathrm{m}}\right)$ was obtained by applying a 0.8 s saturating pulse. Maximal photochemical efficiency of photosystem 2 (PS 2) was calculated as $\mathrm{F}_{\mathrm{v}} / \mathrm{F}_{\mathrm{m}}=\left(\mathrm{F}-\mathrm{F}_{0}\right) / \mathrm{F}_{\mathrm{m}}$, and the quantum yield of PS 2 $\left[\Phi_{\mathrm{PS} 2}=\left(\mathrm{F}_{\mathrm{m}}{ }^{\prime}-\mathrm{F}_{\mathrm{s}}\right) / \mathrm{F}_{\mathrm{m}}{ }^{\prime}\right]$, where $\mathrm{F}_{\mathrm{m}}{ }^{\prime}$ is maximum fluorescence after light-adaptation, and $F_{s}$ steady-state fluorescence (Genty et al. 1989).

Membrane permeability was estimated by measuring electrolyte leakage (EL) according to Blum and Ebercon (1981) using a conductivity meter (DDSJ-308A, Shanghai, China). Malondialdehyde (MDA) was extracted with $10 \%(\mathrm{~m} / \mathrm{v})$ trichloroacetic acid and after reaction with $0.6 \%$ thiobarbituric acid the absorbance was determined at 450, 532, and $600 \mathrm{~nm}$ according to Hodges et al. (1999). RWC was estimated gravimetrically according to Bajji et al. (2001) and the proline content was determined by the method of Bates et al. (1973).

Leaf samples $(0.2 \mathrm{~g})$ were homogenized in $3 \mathrm{~cm}^{3}$ of $50 \mathrm{mM}$ potassium phosphate buffer $(\mathrm{pH}$ 7.8) containing $0.2 \mathrm{mM}$ EDTA and $1 \%(\mathrm{~m} / \mathrm{v})$ polyvinylpyrrolidone, and then centrifuged at $15000 \mathrm{~g}$ for $20 \mathrm{~min}$ at $4{ }^{\circ} \mathrm{C}$. The supernatant was then used for enzymatic activity determinations. Protein content was determined according to the method of Bradford (1976) with bovine serum albumin as a standard. SOD activity was assayed by measuring the ability to inhibit the photochemical reduction of nitroblue tetrazolium using the method of Stewart and Bewley (1980). CAT activity was measured as a decline in absorbance $\mathrm{A}_{240}$ in $50 \mathrm{mM}$ potassium phosphate buffer ( $\mathrm{pH}$ 7.0) according to Abassi et al. (1998). APX activity was measured by a decrease in $\mathrm{A}_{290}$ due to AsA oxidation according to Nakano and Asada (1981). GR activity was measured as a decrease in $\mathrm{A}_{340}$ due to oxidation of NADPH according to Foyer and Halliwell (1976). AsA content was measured in extracts according to the method of Law et al. (1983), and GSH content was determined by the method of Griffith (1980).

The experiment was repeated twice with three replicates each time. The values for the parameters were analyzed by analysis of variance (ANOVA) using SPSS (version 15.0). Means were compared using the Duncan multiple range test at the $5 \%$ probability level.

When subjected to drought stress, leaves of C. bungeana showed curled and severely wilted appearance and subsequent chlorosis for up to $72 \mathrm{~h}$ of treatment. Concurrently, both $\mathrm{Chl} a$ and $\mathrm{Chl} b$ (and hence total Chl) contents decreased significantly in these plants, and this loss of Chl could be related to photoinhibition or ROS formation, as demonstrated by the observed increased lipid peroxidation (Table 1). Moreover, the decrease in Chl content may be attributed to decreased activity of protochlorophyllide reductase (Stobart et al. 1985), the key enzyme that determines the biosynthesis of Chl, or increased activity of Chl-degrading enzyme chlorophyllase (Reddy and Vora 1986). Actually, most of enzymes responsible for the synthesis of $\mathrm{Chl}$ and photosynthesis are affected by drought stress. However, the application of EBR exhibited significant improvement in $C$. bungeana phenotypic appearance, and increased $\mathrm{Chl}$ content in the plants grown with or without drought stress, which suggested that EBR may affected the Chl synthesis as well as photosynthesis ( $\mathrm{Yu}$ et al. 2004). In addition, it was probable that EBR had a protective effect on pigment-protein complexes resulting in decreased degradation of Chl.

The $F_{v} / F_{m}$ value, which serves as a measure of the functional status of the oxygen-evolving complex, is usually used as a sensitive indicator for assessing plant photosynthetic performance, and a decrease in $\mathrm{F}_{\mathrm{v}} / \mathrm{F}_{\mathrm{m}}$ indicates the extent of photoinhibition caused by environmental stresses (Maxwell and Johnson 2000). 
Table 1. The effect of EBR on Chl content, chlorophyll fluorescence, electrolyte leakage, MDA content, RWC, proline content, activities of antioxidative enzymes and contents of low molecular antioxidants in leaves of Chorispora bungeana plants grown in full strength Hoagland solution without (WW) and with (DS) $20 \%$ PEG for $3 \mathrm{~d}$. Means \pm SD of two independent experiments $(n=6)$. Means within a row followed by different letters are significantly different at $P<0.05$ based on Duncan test.

\begin{tabular}{|c|c|c|c|c|}
\hline Parameters & WW & $\mathrm{EBR}+\mathrm{WW}$ & DS & $\mathrm{EBR}+\mathrm{DS}$ \\
\hline Chl $a\left[\mathrm{mg} \mathrm{g}^{-1}\right.$ (f.m.) $]$ & $0.80 \pm 0.01 b$ & $0.83 \pm 0.02 \mathrm{a}$ & $0.55 \pm 0.02 \mathrm{~d}$ & $0.58 \pm 0.01 \mathrm{c}$ \\
\hline $\mathrm{Chl} b\left[\mathrm{mg} \mathrm{g}^{-1}\right.$ (f.m.)] & $0.21 \pm 0.01 \mathrm{a}$ & $0.21 \pm 0.01 \mathrm{a}$ & $0.14 \pm 0.01 b$ & $0.16 \pm 0.01 b$ \\
\hline $\operatorname{Chl}(a+b)\left[\mathrm{mg} \mathrm{g}^{-1}\right.$ (f.m.) $]$ & $1.01 \pm 0.01 \mathrm{a}$ & $1.04 \pm 0.02 \mathrm{a}$ & $0.69 \pm 0.03 c$ & $0.74 \pm 0.01 b$ \\
\hline $\mathrm{F}_{\mathrm{v}} / \mathrm{F}_{\mathrm{m}}$ & $0.80 \pm 0.02 b$ & $0.83 \pm 0.01 \mathrm{a}$ & $0.51 \pm 0.02 \mathrm{~d}$ & $0.57 \pm 0.02 c$ \\
\hline$\Phi_{\mathrm{PS} 2}$ & $0.80 \pm 0.02 \mathrm{a}$ & $0.82 \pm 0.01 \mathrm{a}$ & $0.52 \pm 0.02 c$ & $0.57 \pm 0.03 b$ \\
\hline $\mathrm{F}_{\mathrm{m}}$ & $1.21 \pm 0.10 \mathrm{a}$ & $1.28 \pm 0.09 \mathrm{a}$ & $0.69 \pm 0.03 b$ & $0.74 \pm 0.05 b$ \\
\hline $\mathrm{F}_{0}$ & $0.25 \pm 0.04 \mathrm{~b}$ & $0.21 \pm 0.01 b$ & $0.34 \pm 0.03 a$ & $0.32 \pm 0.01 \mathrm{a}$ \\
\hline electrolyte leakage [\%] & $13.27 \pm 1.32 \mathrm{c}$ & $12.10 \pm 1.29 \mathrm{c}$ & $33.84 \pm 1.16 \mathrm{a}$ & $31.07 \pm 1.21 \mathrm{~b}$ \\
\hline MDA [nmol g ${ }^{-1}$ (f.m.)] & $14.01 \pm 0.74 \mathrm{c}$ & $12.47 \pm 0.71 \mathrm{c}$ & $28.64 \pm 0.77 \mathrm{a}$ & $26.56 \pm 1.03 b$ \\
\hline RWC [\%] & $81.10 \pm 2.52 \mathrm{a}$ & $84.10 \pm 1.41 \mathrm{a}$ & $55.57 \pm 3.19 b$ & $59.33 \pm 1.91 b$ \\
\hline Proline $\left[\mathrm{mg} \mathrm{g}^{-1}\right.$ (f.m.)] & $0.24 \pm 0.01 \mathrm{c}$ & $0.22 \pm 0.01 \mathrm{c}$ & $0.41 \pm 0.01 \mathrm{a}$ & $0.38 \pm 0.01 b$ \\
\hline SOD activity $\left[\mathrm{U} \mathrm{mg}^{-1}\right.$ (protein) $]$ & $4.93 \pm 0.24 c$ & $5.42 \pm 0.37 \mathrm{c}$ & $8.32 \pm 0.22 b$ & $8.87 \pm 0.26 \mathrm{a}$ \\
\hline CAT activity $\left[\mu \mathrm{mol}\left(\mathrm{H}_{2} \mathrm{O}_{2}\right) \mathrm{mg}^{-1}\right.$ (protein) $\left.\mathrm{min}^{-1}\right]$ & $0.44 \pm 0.03 \mathrm{~d}$ & $0.51 \pm 0.03 c$ & $0.86 \pm 0.02 b$ & $0.91 \pm 0.02 \mathrm{a}$ \\
\hline APX activity $\left[\mu \mathrm{mol}\left(\right.\right.$ AsA) $\mathrm{mg}^{-1}$ (protein) $\left.\mathrm{min}^{-1}\right]$ & $1.72 \pm 0.08 \mathrm{~d}$ & $1.98 \pm 0.19 \mathrm{c}$ & $4.33 \pm 0.09 b$ & $4.61 \pm 0.14 \mathrm{a}$ \\
\hline GR activity $\left[\mu \mathrm{mol}(\mathrm{NADPH}) \mathrm{mg}^{-1}\right.$ (protein) $\left.\mathrm{min}^{-1}\right]$ & $0.15 \pm 0.01 \mathrm{c}$ & $0.16 \pm 0.01 \mathrm{c}$ & $0.29 \pm 0.01 b$ & $0.31 \pm 0.01 \mathrm{a}$ \\
\hline AsA $\left[\mu \mathrm{mol} \mathrm{g}{ }^{-1}\right.$ (f.m.) $]$ & $5.16 \pm 0.09 \mathrm{~d}$ & $5.36 \pm 0.07 \mathrm{c}$ & $7.20 \pm 0.14 b$ & $7.58 \pm 0.10 \mathrm{a}$ \\
\hline GSH $\left[\mu \mathrm{mol} \mathrm{g}^{-1}\right.$ (f.m.)] & $8.68 \pm 0.49 \mathrm{c}$ & $8.36 \pm 0.23 c$ & $10.91 \pm 0.20 b$ & $11.62 \pm 0.36 \mathrm{a}$ \\
\hline
\end{tabular}

Compared to well-watered seedlings, $\mathrm{F}_{\mathrm{v}} / \mathrm{F}_{\mathrm{m}}$ and $\Phi_{\mathrm{PS} 2}$ decreased remarkably when $C$. bungeana were exposed to drought stress for $3 \mathrm{~d}$ (Table 1), showing clearly that drought stress caused a considerable injury of photosynthetic apparatus. Similar results were reported by Cai et al. (2010) in Incarvillea delavayi. However, EBR pretreatment reduced the decreases in $\mathrm{F}_{\mathrm{v}} / \mathrm{F}_{\mathrm{m}}$ and $\Phi_{\mathrm{PS} 2}$ in the drought-treated plants, which indicated that exogenous EBR was able to alleviate photoinhibition caused by drought stress and had a strong protective effect on the structure and function of the oxygenevolving complex of PS 2 in these leaves. Similarly, Xia et al. (2009) found that exogenous EBR prevents chilling stress caused photoinhibition in cucumber. The droughtinduced decrease in $\mathrm{F}_{\mathrm{v}} / \mathrm{F}_{\mathrm{m}}$ resulted from concurrent decrease in $F_{m}$ and increase in $F_{o}$ compared to the well watered values. Nevertheless under drought, no significant differences between EBR-pretreated and nonEBR-pretreated $F_{m}$ and $F_{o}$ were observed (Table 1).

Drought stress increased membrane permeability of C. bungeana leaves, but EBR pretreatment significantly ameliorated membrane deterioration (Table 1). In drought-stressed plants, the MDA content, was significantly higher than in the non-drought controls, indicating that pronounced lipid peroxidation occurred under PEG-induced stress. Under drought stress, EBR pretreatment led to greatly reduced MDA content compared with drought stress alone. EBR pretreatment enhanced the RWC of drought-stressed plants, compared with non-pretreated drought-stressed plants whose RWC drastically decreased (Table 1). However, under stressfree conditions, there were no significant differences in membrane permeability, MDA content, and RWC in
EBR-pretreated and control seedlings (Table 1).

Proline performs an important function not only as compatible osmolyte but also in scavenging free radicals and in facilitating corrections of altered redox potentials through replenishment of the $\mathrm{NADP}^{+}$supply (Jain et al. 2001). In stress-free $C$. bungeana plants, the proline content was not significantly changed by EBR pretreatment. There was remarkable increase in proline content in drought-stressed seedlings compared to well watered seedlings, but EBR pretreatment resulted in less increase in proline content in stressed plants (Table 1). One reason might be that the expression of $\Delta^{1}$-pyrroline5-carboxylate synthase, which catalyzes the rate-limiting step of proline biosynthesis, was inhibited by EBR (Ábrahám et al. 2003).

The antioxidative enzyme (SOD, CAT, APX, and GR) activities exhibited increasing trends in response to both drought stress alone and drought with EBR pretreatment (Table 1). However, as shown here and by others (Lee et al. 2009), these enzymes usually did not match the increasing ROS production under severe drought stress. Here, EBR pretreatment significantly enhanced the activities of all these enzymes in droughtstressed plants compared with those of drought-stressed alone (Table 1). Thus, it was clear that EBR increased antioxidative enzyme activities and caused enhancements in the ROS scavenging capacities of these seedlings, resulting in alleviating oxidative injury and concurrently improving the plants resistance to drought stress. Extensive reports have also shown that the application of BRs modified antioxidative enzyme activities under salinity (Ali et al. 2007), and heavy metal stress (Fariduddin et al. 2009). Previous studies have 
demonstrated that elevation of antioxidative enzyme activities by BRs is a gene regulated phenomenon (Xia et al. 2009). Therefore, enhanced antioxidative enzyme activities observed here may have been the result of de novo synthesis and/or activation of the enzymes, mediated through transcription and/or translation of specific genes (Fariduddin et al. 2009).

AsA and GSH are substrates in the AsA - GSH cycle and also act as nonezymatic antioxidants involved in defense against oxidative stress. It is well known that APX and GR are the key enzymes participating in scavenging $\mathrm{H}_{2} \mathrm{O}_{2}$ within a cell via the Asada-Halliwell pathway (Foyer et al. 1994). Lin and $\mathrm{Pu}$ (2010) found that APX activity increased to higher values in salt-stress tolerant sweet potato than in salt-sensitive ones, and the expression of APX isoforms in response to salinity was tissue specific and also dependent on stress duration.

\section{References}

Abassi, N.A., Kushad, M.M., Endress, A.G.: Active oxygen scavenging enzymes activities in developing apple flowers and fruits. - Sci. Hort. 74: 183-194, 1998.

Ábrahám, E., Rigó, G., Székely, G., Nagy, R., Koncz, C., Szabados, L.: Light-dependent induction of proline biosynthesis by abscisic acid and salt stress is inhibited by brassinosteroid in Arabidopsis. - Plant mol. Biol. 51: 363372, 2003.

Ali, B., Hayat, S., Ahmad, A.: 28-Homobrassinolide ameliorates the saline stress in chickpea (Cicer arietinum L). - Environ. exp. Bot. 59: 217-223, 2007.

Bajji, M., Lutts, S., Kinet, J.M.: Water deficit effect on solution contribution to osmotic adjustment as a function of leaf ageing in three durum wheat (Triticum durum Desf.) cultivars performing differently in arid conditions. - Plant Sci. 160: 669-681, 2001.

Bates, L.S., Waldren, R.P., Teare, I.D.: Rapid determination of free proline for water-stress studies. - Plant Soil 39: 205207, 1973.

Blum, A., Ebercon, A.: Cell membrane stability as a measure of drought and heat tolerance in wheat. - Crop Sci. 21: 43-47, 1981.

Bradford, M.M.: A rapid and sensitive method for the quantitation of microgram quantities of protein utilizing the principle of protein-dye binding. - Anal. Biochem. 72: 248254, 1976.

Cai, Y.F., Zhang, S.B., Hu, H., Li, S.Y.: Photosynthetic performance and acclimation of Incarvillea delavayi to water stress. - Biol. Plant. 54: 89-96, 2010.

Clouse, S.D., Sasse, J.M.: Brassinosteroids: essential regulators of plant growth and development. - Annu. Rev. Plant Physiol. Plant mol. Biol. 49: 427-451, 1998.

Correia, M.J., Osório, M.L., Osório, J., Barrote, I., Martins, M., David, M.M.: Influence of transient shade periods on the effects of drought on photosynthesis, carbohydrate accumulation and lipid peroxidation in sunflower leaves. Environ. exp. Bot. 58: 75-84, 2006.

Fariduddin, Q., Yusuf, M., Hayat, S., Ahmad, A.: Effect of 28homobrassinolide on antioxidant capacity and photosynthesis in Brassica juncea plants exposed to different levels of copper. - Environ. exp. Bot. 66: 418-424, 2009.
Here, drought stress caused increases in APX and GR activities, resulting in AsA and GSH accumulation (Table 1). Furthermore, EBR pretreatment enhanced APX and GR activities, and AsA and GSH contents. It was also demonstrated that higher AsA and GSH contents assisted alleviation of drought-induced oxidative damage and partially increased the drought stress tolerance of these seedlings.

In conclusion, the present results could be used to explain the protective role of EBR on Chl content, the photochemical activity of PS 2, membrane lipids and proteins. The ameliorative effects by EBR were closely associated with EBR-induced changes in antioxidative enzyme activities and antioxidant contents. The results here suggested that EBR could improve plant growth under drought stress.

Foyer, C.H., Halliwell, B.: The presence of glutathione and glutathione reductase in chloroplasts: a proposed role in ascorbic acid metabolism. - Planta 133: 21-25, 1976.

Foyer, C.H., Lelandais, M., Kunert, K.J.: Photooxidative stress in plants. - Physiol. Plant. 92: 696-717, 1994.

Foyer, C.H., Noctor, G.: Oxidant and antioxidant signalling in plants: a re-evaluation of the concept of oxidative stress in a physiological context. - Plant Cell Environ. 28: 1056-1071, 2005.

Genty, B., Briantais, J.M., Baker, N.R.: The relationship between the quantum yield of photosynthetic electron transport and quenching of chlorophyll fluorescence. Biochim. biophys. Acta 990: 87-92, 1989.

Griffith, O.W.: Determination of glutathione and glutathione disulphide using glutathione reductase and 2-vinylpyridine. - Anal. Biochem. 106: 207-212, 1980.

Hodges, M.D., Delong, J.M., Forney, C.F., Prange, R.K.: Improving the thiobarbituric acid-reactive-substances assay for estimating lipid peroxidation in plant tissues containing anthocyanin and other interfering compounds. - Planta 207: 604-611, 1999.

Jain, M., Mathur, G., Koul, S., Sarin, N.B.: Ameliorative effects of proline on salt stress-induced lipid peroxidation in cell lines of groundnut (Arachis hypogea L.). - Plant Cell Rep. 20: 463-468, 2001.

Law, M.Y., Charles, S.A., Halliwell, B.: Glutathione and ascorbic acid in spinach (Spinacia oleracea) chloroplasts. The effect of hydrogen peroxide and paraquat. - Biochem. J. 210: 899-903, 1983.

Lee, B.R., Li, L.S., Jung, W.J., Jin, Y.L., Avice, J.C., Ourry, A., Kim, T.H.: Water deficit-induced oxidative stress and the activation of antioxidant enzymes in white clover leaves. Biol. Plant. 53: 505-510, 2009.

Lichtenthaler, H.K.: Chlorophylls and carotenoids: pigments of photosynthetic biomembranes. - Methods Enzymol. 148: 350-382, 1987.

Lin, K.H., Pu, S.F.: Tissue- and genotype-specific ascorbate peroxidase expression in sweet potato in response to salt stress. - Biol. Plant. 54: 664-670, 2010.

Maxwell, K., Johnson, G.N.: Chlorophyll fluorescence - a practical guide. - J. exp. Bot. 51: 659-668, 2000.

Moran, J.F., Becana, M., Iturbe-Ormaetxe, I., Frechilla, S., 
Klucas, R.V., Aparicio-Tejo, P.: Drought induces oxidative stress in pea plants. - Planta 194: 346-352, 1994.

Murashige, T., Skoog, F.: A revised medium for rapid growth and bioassays with tobacco tissue cultures. - Physiol. Plant. 15: 473-497, 1962

Nakano, Y., Asada, K.: Hydrogen peroxide is scavenged by ascorbate specific peroxidase in spinach chloroplasts. Plant Cell Physiol. 22: 867-880, 1981.

Ogweno, J.O., Song, X.S., Shi, K., Hu, W.H., Yu, J.Q., Nogues, S.: Brassinosteroids alleviate heat-induced inhibition of photosynthesis by increasing carboxylation efficiency and enhancing antioxidant systems in Lycopersicon esculentum. - J. Plant Growth Regul. 27: 49-57, 2008.

Reddy, M.P., Vora, A.B.: Changes in pigment composition, Hill reaction activity and saccharide metabolism in bajra (Pennisetum typhoides $\mathrm{S} \& \mathrm{H}$ ) leaves under $\mathrm{NaCl}$ salinity. Photosynthetica 20: 50-55, 1986.

Santos, M.G., Ribeiro, R.V., Machado, E.C., Pimentel, C.: Photosynthetic parameters and leaf water potential of five common bean genotypes under mild water deficit. - Biol.
Plant. 53: 229-236, 2009.

Stewart, R.R.C., Bewley, J.D.: Lipid peroxidation associated with accelerated aging of soybean axes. - Plant Physiol. 65: 245-248, 1980.

Stobart, A.K., Griffits, W.T., Bukhari, I., Sherwood, R.P.: The effect of $\mathrm{Cd}^{2+}$ on the biosynthesis of chlorophyll in leaves of barley. - Physiol. Plant. 63: 293-298, 1985.

Veljovic-Jovanovic, S., Kukavica, B., Stevanovic, B., NavariIzzo, F.: Senescence and drought-related changes in peroxidase and superoxide dismutase isoforms in leaves of Ramonda serbica. - J. exp. Bot. 57: 1759-1768, 2006.

Xia, X.J., Wang, Y.J., Zhou, Y.H., Tao, Y., Mao, W.H., Shi, K., Asami, T., Chen, Z.X., Yu, J.Q.: Reactive oxygen species are involved in brassinosteroid-induced stress tolerance in cucumber. - Plant Physiol. 150: 801-814, 2009.

Yu, J.Q., Huang, L.F., Hu, W.H., Zhou, Y.H., Mao, W.H., Ye, S.F., Nogues, S.: A role of brassinosteroids in the regulation of photosynthesis in Cucumis sativus. - J. exp. Bot. 55: 1135-1143, 2004. 